\title{
SUCCESS OF OSPREY NEST PLATFORMS NEAR LOON LAKE, SASKATCHEWAN
}

\author{
FRANK SCOTT, Box 90, Loon Lake, Saskatchewan SOM 1 L0 and C. STUART \\ HOUSTON, 863 University Drive, Saskatoon, Saskatchewan. S7N 0j8
}

In an effort to help the Ospreys and facilitate our banding we have in four different years moved Osprey nests from dead trees onto platforms. The initial report on Osprey nest success mentioned the first three platforms placed on 25 and 26 March 1978, one without any nesting material. ${ }^{1}$ One platform was used that year, with three young banded 22 July 1978, but was not successful again, although Ospreys were in attendance in both 1979 and 1980. One occupancy in 5 years with 3 platiorms available is a discouraging record.

In July 1981 farther east along the north shore of Loon Lake, the junior author somewhat nervously climbed 39 feet to the top of a dead spruce to band three young. In 1982 this dead tree had tipped 45 degrees; by sheer coincidence and against 360 to 1 odds it fell exactly so that an adjacent live spruce supported both the tree and the nest. With great difficulty Ken Simes climbed the live spruce and gingerly banded two young Ospreys in the precariously lodged nest. During the first storm after the young fledged, the nest tree fell completely down. Clearly something had to be done.

Platform building resumed 19 and 20 March 1983. The party consisted of Ron Marlatte and Jim Slimmon from Saskatoon, Bruce Donovan from Nipawin and Bert Dalziel from White Fox, together with the authors. The nearest sound tree, on a gravel ridge less than 100 yards across a narrow swamp from the lakeshore, was lopped off at a height of about 18 feet, a platform constructed, and contents of the old nest moved onto it. Although easily visible to any fisherman who looks for it, its position allows the incubating Osprey a magnificent view of the lake. On 16 July 1983 three young were banded on this platform and on 15 July 1984 two smaller young were banded.

On 11 July 1985 two young were seen from the air by the senior author, but they were missing by the banding visit of $14 \mathrm{Ju}$ ly. A large person or animal had moved through the adjacent underbrush recently; there was a freshly broken branch part way up to the platform, and no bear or racoon claw marks were visible. It is unimaginable why any human would take two young Ospreys as pets, but 3 years ago a man was apprehended for chopping down a tree beside Highway 21, to obtain the young Ospreys in the nest. One of them was killed by the fall; the man received a $\$ 200$. fine.

The other two platforms in 1983 were placed on the south side of Ministikwan Lake, one on a hill at some distance from the lake but with a clear view of the water, and the other without a view of the lake. These have not been used.

On 17 and 18 March 1984 the helpers consisted of Ron Jensen, Sean Morrissey and Richard McBride. In a large dead Jack Pine on the shore of Tullibee Lake, young had been banded at some risk by Tim Molnar 19 July 1981 and by Kelly Wylie 16 July 1983, in a nest at a height of $50 \mathrm{ft}$. This tree was reduced to a safer height of 22 feet. Although the original nest materials were placed on the platform and although a superb view of the lake was available for the incubating Osprey, this platform has not yet been used. 


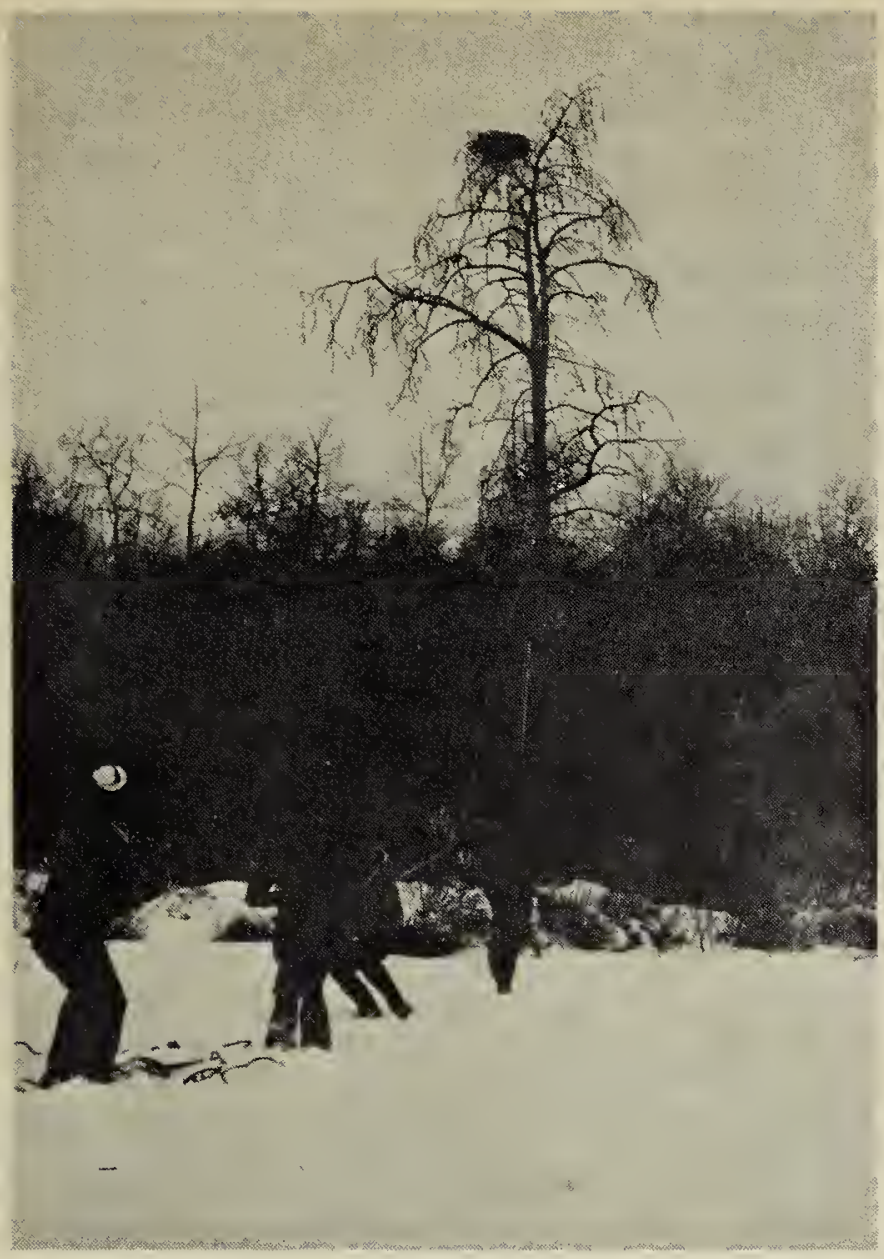

Moving a nest from a $50+\mathrm{ft}$. Jack Pine on 1984.

A second platform was placed on a hill east of Peck Lake. In 1983 the nest was balanced precariously on two stems of a dead Jack Pine, $49 \mathrm{ft}$. above the ground, so that the young could not be safely banded. A platform was constructed $35 \mathrm{ft}$. above ground and the nest lowered onto it. The two $14 \mathrm{ft}$. stems, each little more than an inch in diameter, were dead and extremely brittle; it was amazing that they had withstood previous storms. The new platform allowed a view of the lake and was successful with two young banded in each of 1984 and 1985.

On 9 March 1985 a platform-building crew consisted of Kelly Wylie, Dan Neves, Bert Dalziel and Bruce Donovan. At the north end of Upper Makwa Lake a platform was placed $28 \mathrm{ft}$. above ground in a Jack Pine, after removing the dead upper part of the tree. The nest was moved from an adjacent dead Jack Pine which was then cut down.

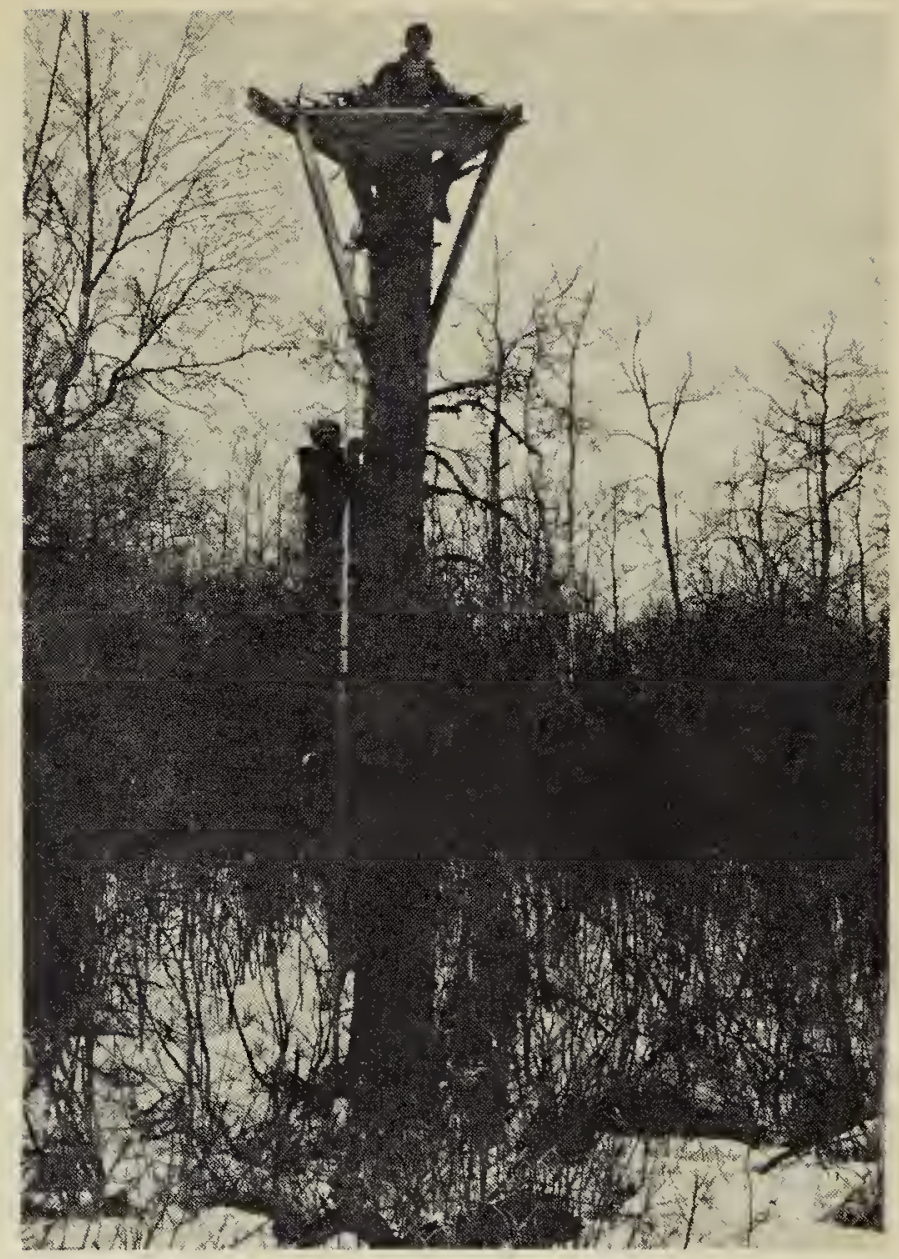

Tullibee Lake to a platform 17 March

Ron Jensen

Another nest was in a single Tamarack in a swampy bay at the southwest corner of Upper Makwa Lake. This tree was precarious indeed and could almost be pushed over. A platform was placed $26 \mathrm{ft}$. from the ground in the nearest adjacent Tamarack. Both of the new platforms raised young and three were banded at each 13 July 1985.

\section{Discussion}

Our two motives in placing these platforms fortunately do not conflict. Admitted$l y$, it is desired to have a higher percentage of Osprey nests in trees that are safe to climb. Most tall, dead trees are unsafe. A nest weighing more than half a ton, placed at the very top of a dead tree also forms a potential risk for the young Ospreys. When the nest tilts during a storm, the eggs may roll out. If the tree blows over, the young nearly always die. Furthermore, platforms offer less susceptibility to wind damage and greater security from ground predators. In 
Nova Scotia, Ospreys are $20 \%$ more successful when they nest on utility poles than when they nest in natural trees. ${ }^{2}$ In Florida there is less egg loss at artificial platforms, resulting in about twice as many young per active nest, when platforms are used. ${ }^{3}$

Since this study began in 1975 no Osprey pair has built a nest and raised young the same year. When a tree at risk of blowing over is correctly identified there is hope of saving that year's production as well as a second year of nest building.

Rather than guessing at the location a previously occupied site is chosen. Chances of success are much greater if the platform height allows the incubating Osprey to see the surface of the lake and if the platform tops the trees within a radius of 20 or preferably $40 \mathrm{ft}$. on three sides of the nest.

The basic support structure of our platforms has not changed (Fig. 1). It consists of four pieces, each $8 \mathrm{ft}$. long of $2 \times 6^{\prime \prime}$ lumber. To expedite building, all holes are predrilled and carriage bolts put in loosely. Each pair of 8-foot planks, hinged together by a loose carriage bolt, is raised by rope to the desired level. The upper lag bolt is fastened securely to the tree with one plank horizontal, then the lower end of the oblique support plank is fastened to the tree by another lag bolt. The horizontal planks are arranged to diverge outward on the side of the tree facing the lake, forming an adequate angle to support a platform. One plank protrudes $2 \mathrm{ft}$. on the opposite side of the tree to the platform and gives the bander an adequate perch from which to work. The other protrudes beyond the platform as a perch for the birds. Four crosspieces, of increasing length, are nailed to the planks to form a V-shaped platform. After final tightening of lag bolts, the sticks from the previous year's Osprey nest are raised onto the edges of the platform and then the fine material from the nest depression, including fish scales, is formed into a smooth, depressed cup.

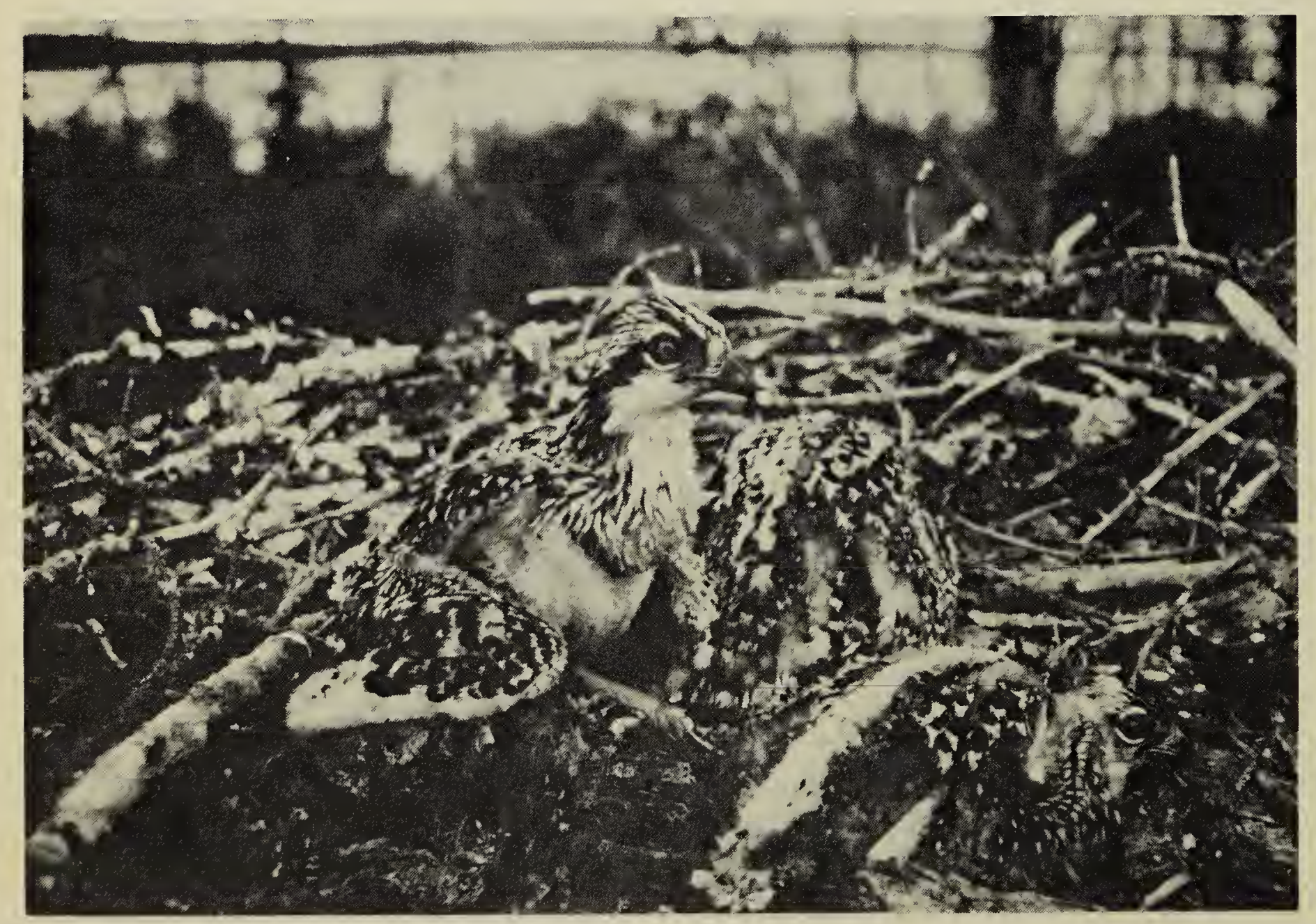

Two Osprey nestlings on new platform, Loon Lake, 16 July 1983

Hans S. Dommasch 

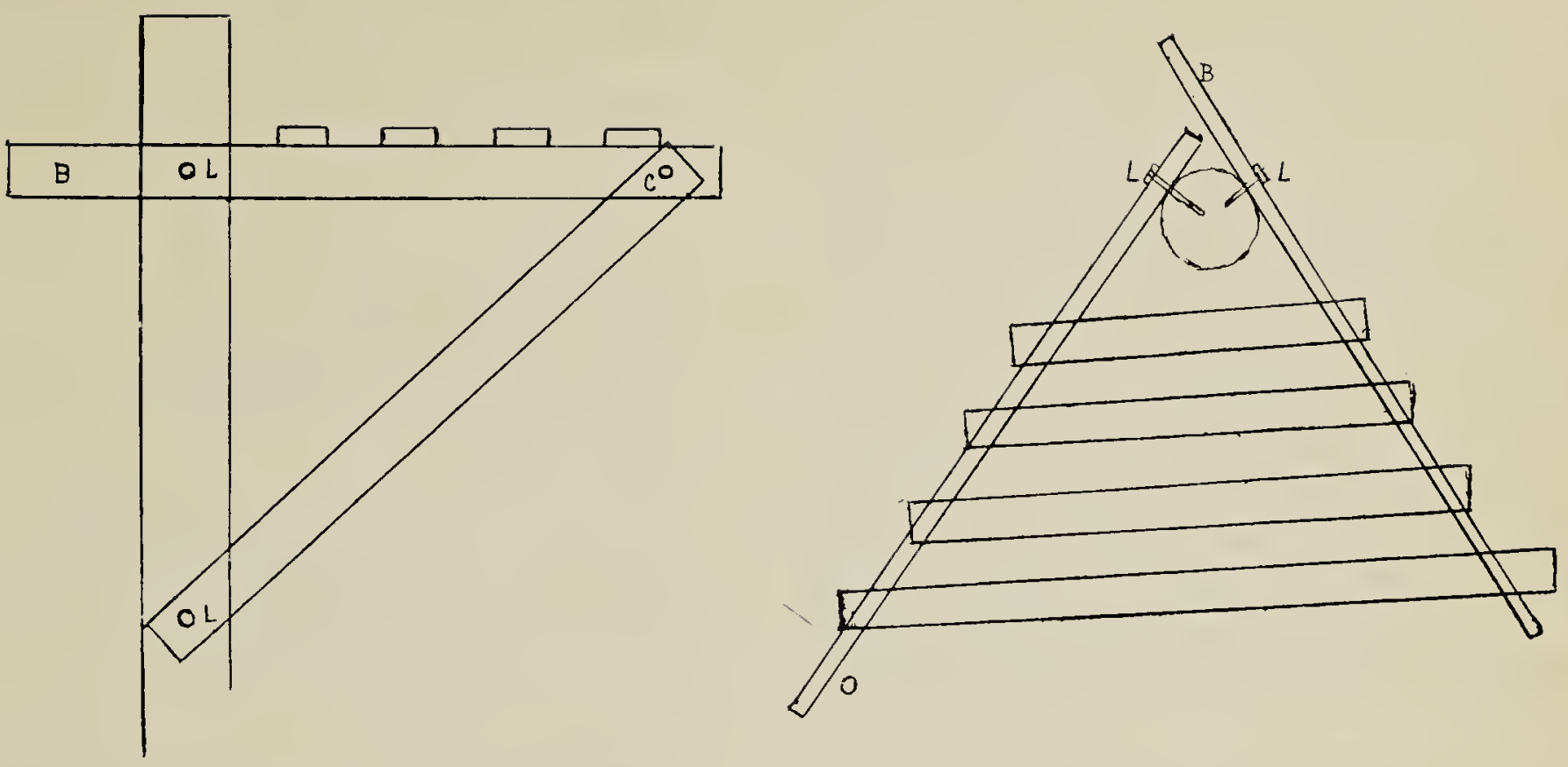

Figure 1. The new nest platform structure. B - bander's perch; C - carriage bolt; L - lag bolt; O - Osprey perch

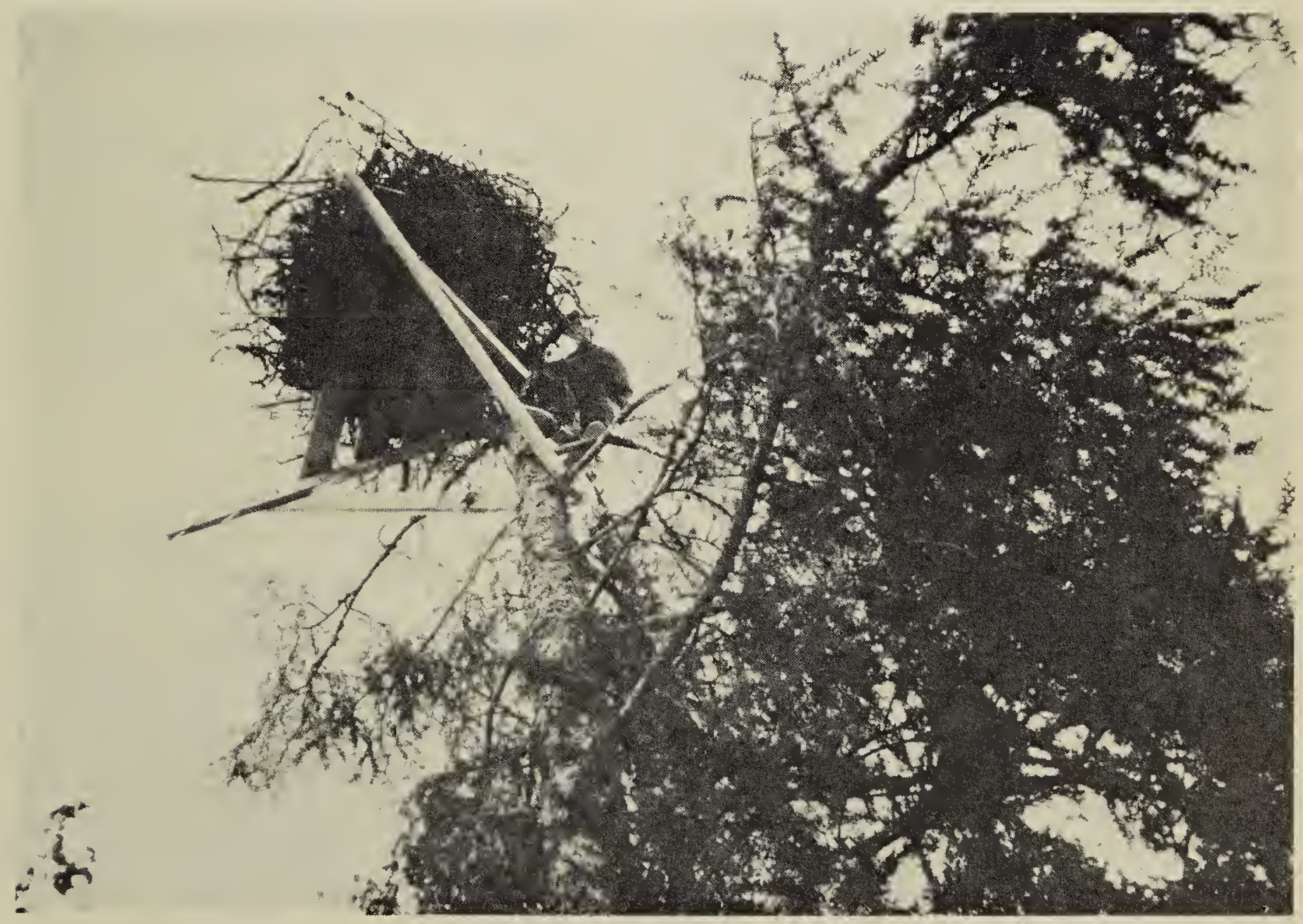

Stuart Houston banding nestlings at Osprey platform near Peck Lake, 13 July 1985

Mary I. Houston 
Using locally cut lumber, the price of each platform is now approximately $\$ 15.00$, including hardware and nails. The first year we used half sheets of $1^{\prime \prime}$ plywood $(4 \mathrm{ft} . x$ $4 \mathrm{ft}$.). To keep nest material on the platform $0.5^{\prime \prime}$ dowels $6^{\prime \prime}$ long were inserted vertically close to the periphery of the plywood. The resulting platform was heavy to lift up to the top of the tree, was very expensive and did not allow rapid drainage after a rain. After the first three platforms the above design of $2 \times 6^{\prime \prime}$ cross pieces fastened to the horizontal supports with $3.5^{\prime \prime}$ nails was used. This structure is both cheaper and lighter to lift. Any cutting necessary on site is done with a small chain saw, neither elegant nor precise, but quick and easy.

Success rate is improving -- three of the last four platforms constructed have been used. Including the 1978 construction five of ten platforms built have been used successfully at least once.

The number of unsafe trees, at risk of blowing over in a storm, has been reduced from eight in 1982 to six each in 1983 and 1984 and four in 1985. Another dead tree, in a large slough south of Loon Lake, is inaccessible in summer. Another nest south of Ministikwan Lake is $0.5 \mathrm{mi}$. from water, would be difficult to reach in summer and no adjacent tree would allow a view of the water. Such sites are not prac- tical for replacement. However, there are two excellent and appropriate sites chosen for the March 1986 work party. It is also planned to trim off the new branch that has sprouted above the platform built in 1978 and to clear away several nearby trees that may restrict the Ospreys' approach.

\section{Acknowledgements}

Financial support for the costs of materials was supplied by the Saskatchewan Natural History Society.

The increasing success rate is heartening. Experience has enabled us to avoid repetition of some of our earlier errors.

1 HOUSTON, C.S. and FRANK SCOTT 1983 Osprey nesting success in west-central Saskatchewan. Blue Jay $41(1): 27-32$

2 SEYMOUR, N.R. and R.P. BANCROFT 1983 The status and use of two habitats by Ospreys in northeastern Nova Scotia. Pp. 275-281 In Biology and Management of Bald Eagles. Edited by D.M. BIRD, N.R. SEYMOUR and J.M. GERRARD. Harpell Press, Ste. Anne de Bellevue, Quebec.

${ }^{3}$ WESTALL, M.A. 1983 An Osprey population aided by nest structures on Sanibel Island Florida. Pp. 287-293 In Biology and Management of Bald Eagles. Edited by D.M. BIRD, N.R. SEYMOUR and J.M. GERRARD. Harpell Press, Ste. Anne de Bellevue, Quebec.

\section{ENDANGERED SPECIES WORKSHOP}

A workshop on endangered species in the prairie provinces will be held at the Provincial Museum of Alberta, 12845 - 102 Avenue, Edmonton, 24-25-26 January 1986. Presentations on 10 rare, threatened and endangered species in the prairie, aspen parkland and boreal forest ecoregions of Canada will be made in the auditorium.

At working sessions participants will discuss education, habitat conservation and the status and conservation needs for 15 other species. Two live endangered species will be on display, along with exhibits on prairie wildlife. Proceedings are to be published. Registration fee for the workshop is $\$ 10$. and the fee for the banquet is $\$ 20$. To register and for more information contact Endangered Species Workshop, Federation of Alberta Naturalists, Box 1472, Edmonton, Alberta T5J 2N5, or phone Ms. Jo Wiskerke 403-428-3033 or Dave Ealey 403-434-0841. Participants must pre-register by mail. Please submit registrations by 31 December 1985. 